\title{
Returning the State Aid Heart to our Island States
}

A recent Disney movie-night triggered reflection on the 'special' position of islands under the current State aid rules. Moana, daughter of the village chief, and her fellow inhabitants of the island of Motunui worship the goddess Te Fiti, who brought life to the ocean. With the support of the goddess, life on the island is happy and production abundant. Indeed, before the State aid modernisation (SAM) initiative and statistical enlargement effects, aid schemes helped to (at least partly) overcome certain challenges faced by manufacturing companies in our small island states.

Small islands are often very popular tourist destinations. However, it is widely recognised that these islands face multiple challenges in developing and maintaining economic activity. These challenges are probably most pronounced for manufacturing. Higher transport costs, elevated inventory costs, a small domestic market as well as expensive utilities and the need for vertical integration merely constitute some examples. Without compensatory measures to help overcome these difficulties, it is very unlikely that manufacturing companies opt for an island location. At the same time, the few manufacturers that started their manufacturing business on an island increasingly follow opportunities to settle on the mainland. This tendency is accelerated the more an island is situated in the periphery of the European Union. As a result, we observe for instance that - in Malta - the manufacturing share of GDP has declined from $22.4 \%$ in 2000 to currently below $10 \%$. Nevertheless, EU policy makers stress the importance of a balanced economy where the rate of manufacturing is increased to $20 \%$. Obtaining this goal obviously becomes more difficult when some of the Member States witness a rapid decline of manufacturing activity, certainly when this activity is not relocated towards the EU mainland, but also towards other countries nearby. The declining share of manufacturing has been highly disruptive to the Maltese economy.

Luckily, as Te Fiti protects the island of Motunui and its inhabitants, the EU as well as the EU Member States have developed solidarity mechanisms to help small islands overcome their challenges, just as these policies help peripheral, sparsely populated and underperforming areas. For some of these regions, Article 349 TFEU even explicitly asks for 'specific measures'. Included in this list are regions that are part of a Member State and that can hence also rely on the solidarity mechanisms of the country they belong to. When the island is, however, not part of a larger country, it obviously cannot draw on that country's solidarity mechanisms. The advantage of being an island state is that it can adopt general measures without bumping into constraints posed by geographical selectivity. However, these general measures are obviously also limited if the island aims to keep a healthy budget balance. Indeed, for an island Member State, only the EU (cf EU Cohesion policy) and limited possibilities under the EU State aid rules can truly support the island in keeping its attractiveness for manufacturing companies. The State aid framework has thus been important in allowing aid measures to level the playing field with the mainland and with the economic core of the Union.

The support of Te Fiti is of crucial importance for the inhabitants of Motunui. However, demigod Maui steals the heart of Te Fiti to give more power to humanity. Unfortunately, he 
subsequently loses the heart in a fight and Te Fiti is no longer able to help the island of Motunui. This completely changes island life and harvests fail. Indeed, demigod SAM and subsequent changes to the General Block Exemption Regulation (GBER) and the Regional Aid Guidelines (RAG), together with statistical enlargement effects, have lost the State aid heart for island Member States as the GBER and RAG now fall short in their treatment of (island state) manufacturing. Compensating high transport costs is only allowed for outermost and sparsely populated regions (similar for operating costs). It is intriguing that other Guidelines still treat Malta and Cyprus together with the outermost regions. This seems nonetheless plausible as the challenges faced by the island Member States are also permanent and do not disappear because, for instance, GDP per capita has increased to the threshold of $75 \%$ of the EU average. This thus makes us wonder why outermost regions and island Member States cannot be treated equivalently when it comes to transport and operating costs.

Moana is chosen by the ocean to find and return Te Fiti's heart. She succeeds, restoring activity and happiness on the island of Motunui. The following question remains yet unanswered: where will we find our Moana to restore the State aid heart for manufacturing in our island Member States? While the Commission can certainly take on this role by making a small change to the GBER or the RAG to fill the vacuum in the State aid rules, it could also be done by all Member States together. The inclusion of our two small and peripheral island Member States in Article 349 TFEU would indeed also constitute a solution. While I see the reason why Malta and Cyprus, being island states, were not included in this article during its conception, I currently find more weighty arguments for their incorporation. If I were Malta or Cyprus, even though a small change in the GBER or RAG is probably more realistic and even though a Treaty change is highly unlikely, I would never let it go.

Caroline Buts 